\title{
EFICIÊNCIA ENERGÉTICA EM PRÉDIOS DE SALAS DE AULA NATURALMENTE VENTILADOS
}

\section{ENERGY EFFICIENCY IN NATURALLY VENTILATED CLASSROOM BUILDINGS}

\author{
Wagner Costa Oliveira ${ }^{1}$ \\ Universidade Federal de Pelotas, Pelotas, RS, Brasil, wenver@gmail.com \\ Rodrigo Karini Leitzke ${ }^{2}$ \\ Universidade Federal de Pelotas, Pelotas, RS, Brasil, rodrigokarinileitzke@gmail.com \\ Eduardo Grala da Cunha ${ }^{3}$ \\ Universidade Federal de Pelotas, Pelotas, RS, Brasil, eduardogralacunha@yahoo.com.br
}

\begin{abstract}
Resumo
Em 2014, foi publicada a Instrução Normativa 02/2014, do Ministério do Planejamento, Desenvolvimento e Gestão, obrigando os projetos de edificações e os retrofit de edificações públicas federais, com mais de quinhentos metros quadrados de área, a serem desenvolvidos buscando a Etiqueta Nacional de Conservação de Energia de Projeto nível A, de acordo com os Requisitos Técnicos de Qualidade para o Nível de Eficiência Energética de Edifícios Comerciais, de Serviços e Públicos (RTQ-C). O objetivo deste trabalho é verificar se projetos de prédios de salas de aula licitados por Instituições Federais de Ensino Superior (IFES) atendem à determinação da IN 02/2014 e, em caso negativo, como intervir para os projetos atingirem nível A. Foram analisados dez prédios naturalmente ventilados licitados por quatro IFES do Rio Grande do Sul, seguindo os procedimentos indicados no RTQ-C. Também foram realizadas simulações para verificar o consumo hipotético de energia se os edifícios fossem condicionados artificialmente. Como resultado, $60 \%$ dos projetos conseguiram alcançar o nível mais alto de eficiência energética, atendendo à Instrução Normativa. Também se verificou que, nos casos negativos, a substituição das lâmpadas tubulares fluorescentes por lâmpadas LED equivalentes e especificação de bacias sanitárias econômicas bastaria para os projetos obterem a classificação máxima.
\end{abstract}

Palavras-chave: Simulação de eficiência energética. RTQ-C. Edifícios públicos. Ventilação natural.

\begin{abstract}
Normative Instruction 02/2014 was published in 2014 by the Ministry of Planning, Development, and Management. It binds building design and retrofit of public buildings with more than five hundred square meters of area, to be developed according to the National Label of Energy Conservation level A of the Technical Standards for the Quality of Commercial, Services and Public Buildings (RTQ-C). This paper's objective is to verify if the energy efficiency level in classroom buildings, which were bidden by Federal Institutions of Higher Learning (IFES), meets the NI's resolutions and, if not, how they can be improved. Following RTQ-C's protocol, ten naturally ventilated buildings, bidden by four different IFES, were analyzed. Simulations were run verifying the hypothetical energy expenditure if the buildings were air-conditioned. As a result, $60 \%$ of the buildings met the highest grade of energy efficiency, complying with the NI. In non-compliance, small modifications such as the replacement of fluorescent light tubes by LED lights and dual flush toilets are enough for the projects to reach the level A-label.
\end{abstract}

Keywords: Energy efficiency simulation. RTQ-C. Public buildings. Natural ventilation.

How to cite this article:

OLIVEIRA, W. C.; CUNHA, E. G. DA; LEITZKE, R. K. Eficiência energética em prédios de salas de aula naturalmente ventilados. PARC Pesquisa em Arquitetura e Construção, v. 11, p. e020015, 7 ago. 2020. DOI:

https://doi.org/10.20396/parc.v11i0.8655373 


\section{Introdução}

A questão energética tem sido foco de maior atenção no Brasil desde 2001, quando o aumento do consumo de eletricidade, aliado à ausência de planejamento de investimentos no setor e condições climáticas desfavoráveis, levou a um racionamento de energia no país (ARAUJO, 2001). Desde então, intensificaram-se as ações visando aumentar a economia de energia e combater seu desperdício.

No âmbito da Administração Pública Federal, foram emitidos alguns Decretos com o objetivo de reduzir o consumo de energia em seus prédios. Em seguida, foi criada a Lei 10.295, conhecida como Lei de Eficiência Energética (BRASIL, 2001), reforçando a necessidade de criar metodologias para a verificação do consumo energético e nível de eficiência de máquinas e equipamentos fabricados e comercializados no país, assim como nas edificações.

Como resultados dessas iniciativas, os anos seguintes representaram um grande avanço para os estudos sobre a eficiência energética nos edifícios. Em 2003 criou-se o PROCEL Edifica, um programa específico para alcançar prédios mais eficientes. Dois anos depois, foi publicada a NBR 15220 (ABNT, 2005), que trata do desempenho térmico de edificações, e também traz o Zoneamento Bioclimático Brasileiro, com diretrizes construtivas para melhorar o desempenho térmico das edificações habitacionais unifamiliares de interesse social através da adoção de estratégias passivas de condicionamento.

A preocupação da Administração Pública é expoente acerca da questão da inclusão da sustentabilidade em seus processos de licitação, criando uma série de legislações para regulamentar os aspectos de sustentabilidade nas contratações públicas. Em 1999, o Governo Federal iniciou um projeto denominado Agenda Ambiental na Administração Pública ( $\mathrm{A} 3 \mathrm{P}$ ), com o objetivo de incentivar as instituições públicas a adotar padrões de produção e consumo mais sustentáveis. O programa de mesmo nome, iniciado em 2001, visava "sensibilizar os gestores públicos para a importância das questões ambientais, estimulando-os a incorporar princípios e critérios de gestão ambiental em suas atividades rotineiras" (BRASIL, 2009, p. 30). Dentro dos cinco eixos de atuação do programa, a existência de um eixo específico dedicado à questão das compras públicas sustentáveis mostra que o Estado tem consciência da influência que exerce tanto na sociedade quanto no mercado, no papel de grande consumidor de produtos e serviços.

Oliveira e Santos (2015) destacam a necessidade dos entes públicos utilizarem seu poder de compra para influenciar o mercado, através da escolha de bens e serviços por critérios econômicos (melhor relação custo-benefício), ambientais (análise do ciclo de vida dos produtos) e sociais (favorecimento de cooperativas populares ou empreendimentos de economia solidária). Os autores ainda acreditam que "O Estado, por meio de seu grande poder como comprador, poderá reverter impactos sociais e ambientais advindos do processo produtivo, incentivando organizações que não tenham como princípio primeiro a busca do lucro individual" (OLIVEIRA; SANTOS, 2015, p. 203).

Em 2009, foi publicada pela primeira vez a versão final dos Requisitos Técnicos de Qualidade para o Nível de Eficiência Energética de Edifícios Comerciais, de Serviços e Públicos (RTQ-C), definindo os critérios de desempenho e metodologias de etiquetagem do nível de eficiência energética para estas edificações. Quando observados, os padrões construtivos do RTQ-C (INMETRO, 2010) podem resultar em uma economia de energia de até $50 \%$ para prédios novos e $30 \%$ em caso de reformas (PROCELINFO, 2006). Assim, o processo de etiquetagem das edificações mostra-se como uma importante ferramenta de economia de energia. 
A Instrução Normativa 02/2014, publicada pela Secretaria de Logística e Tecnologia da Informação do Ministério de Planejamento, Desenvolvimento e Gestão (SLTI/MP), foi uma importante adição ao conjunto de normas sobre eficiência energética. Desde sua vigência, tornou-se obrigatório que os projetos de edificações públicas federais, com mais de quinhentos metros quadrados, fossem desenvolvidos para obter a Etiqueta Nacional de Conservação de Energia (ENCE) nível A. A determinação é válida tanto para prédios novos como para reformas em edificações.

Esta preocupação com o consumo de eletricidade nos prédios públicos torna-se mais importante ao conhecermos os dados do último relatório do Balanço Energético Nacional (EPE, 2018), relativo ao ano de 2017. Os edifícios no Brasil foram responsáveis pelo uso de 267,5 TWh de energia elétrica, equivalente a $50,83 \%$ do total consumido no país. No que tange às edificações públicas, o consumo foi de $43,3 \mathrm{TWh}$, correspondente a $8,23 \%$ da eletricidade utilizada no período. Em valores absolutos, ocorreu um aumento de 8,75 TWh no consumo das edificações públicas nos últimos dez anos, representando um crescimento de 25,34\% em relação aos dados de 2008 .

A obrigatoriedade da etiquetagem das obras públicas pode, portanto, contribuir para a redução do consumo dessa parcela de edificações, além de incentivar e difundir a avaliação da eficiência energética dos prédios brasileiros.

\section{Revisão Bibliográfica}

Foram analisados alguns trabalhos de pesquisa que utilizaram o RTQ-C (INMETRO, 2010) como base para a avaliação da eficiência energética de edificações públicas, comerciais e de serviços.

Silva e Pagel (2017) verificaram a eficiência energética do edifício do DETRAN/ES, na cidade de Vitória. Após o levantamento das características físicas e das atividades desenvolvidas no prédio, foi realizada a classificação do edifício utilizando o webprescritivo, sistema criado pelo Laboratório de Eficiência Energética em Edificações da Universidade Federal de Santa Catarina. Por fim, após a análise dos resultados, foram sugeridas intervenções projetuais para melhorar a classificação. Após a obtenção dos resultados (a envoltória recebeu a classificação $\mathrm{E}$, principalmente por causa da cobertura deficiente; a iluminação obteve nível C, devido ao não atendimento do prérequisito de contribuição da luz natural; e o condicionamento de ar alcançou o melhor nível), escolheu-se o sistema de pior desempenho para a proposição de intervenções. Com a instalação de isolamento térmico de lã de vidro e forro de PVC, as pesquisadoras constataram que a envoltória do prédio alcançaria o nível A de eficiência, comprovando assim que pequenas intervenções podem ter grandes resultados na economia de energia e melhoria do desempenho da edificação.

Nakamura, Maciel e Carlo. (2013) utilizaram uma variação do método de simulação computacional do RTQ-C (INMETRO, 2010) para avaliar o impacto da implantação de diferentes medidas de conservação de energia no conforto térmico do prédio de laboratórios de engenharia da Universidade Federal de Viçosa. Ao todo, 16 hipóteses de intervenções foram avaliadas, incluindo a utilização de panos de vidro paralelos às fachadas com câmara de ar, variações nos brises horizontais e verticais das janelas, alteração nas aberturas zenitais com vidros de diferentes fatores solares e alterações na absortância das paredes externas. Os autores constataram que as alternativas que promoviam o aquecimento da edificação com panos de vidro e câmaras de ar obtiveram resultados de conforto melhores que o caso-base, enquanto a utilização de dispositivos de sombreamento reduziu o percentual de horas em conforto nos ambientes do edifício. Em sua conclusão, o trabalho também ressalta que o método escolhido para o 
estudo (média ponderada do percentual de horas totais em conforto) tem impacto positivo no equivalente numérico da edificação, quando comparado ao método proposto pelo RTQ-C (INMETRO, 2010).

Fossati e Lamberts (2010) discutiram a eficiência energética da envoltória de dez edifícios de escritórios na cidade de Florianópolis, através das variáveis consideradas nas equações do método prescritivo do RTQ-C (INMETRO, 2010), desconsiderando a avaliação dos pré-requisitos específicos do sistema. Os autores verificaram que o percentual de aberturas na fachada é o fator que mais influencia no cálculo do nível de eficiência, seguido pela presença de dispositivos de sombreamento; por outro lado, destacam que o fator solar dos vidros tem pouca relevância nesse aspecto.

\section{Objetivos}

O objetivo geral deste trabalho é avaliar o nível de eficiência energética de prédios de salas de aula licitados pelas IFES do Rio Grande do Sul, localizados na Zona Bioclimática 2.

São objetivos específicos da pesquisa:

a) Analisar os resultados obtidos em cada etapa da metodologia do RTQ-C (INMETRO, 2010), a fim de identificar as deficiências em cada um dos sistemas avaliados de cada projeto;

b) Propor alterações nos projetos avaliados, caso necessárias, visando melhorar suas pontuações para que atinjam o nível A de eficiência energética;

c) Verificar e comparar o consumo de energia dos prédios após a proposição dos melhoramentos, na hipótese de condicionamento artificial dos ambientes de trabalho.

\section{Método}

O trabalho dividiu-se em cinco etapas principais: a aquisição dos dados de pesquisa, a descrição dos dados obtidos; a verificação da eficiência energética dos projetos selecionados; a proposição de alterações nos projetos, baseadas nos resultados obtidos na aplicação do método do RTQ-C (INMETRO, 2010); e a verificação do consumo energético dos edifícios melhorados, na hipótese de serem condicionados artificialmente.

\section{Objetos de Estudo}

Foram selecionados para este estudo dez projetos de prédios de salas de aula naturalmente ventiladas, localizados em cidades da Zona Bioclimática 2, de acordo com o Zoneamento Bioclimático Brasileiro (ABNT, 2005). Estes projetos foram licitados no período inicial da vigência da IN 02/2014, ou seja, entre agosto de 2014 e dezembro de 2016. Os projetos foram obtidos através do Portal de Compras Governamentais (2018), utilizando seu mecanismo de pesquisas. A Figura 1 apresenta uma ilustração de cada prédio analisado, elaborada com base nos modelos construídos para a simulação de eficiência energética.

A seguir, serão apresentados os dados específicos de cada projeto, organizados em dois grupos. No primeiro conjunto de dados, introduzidos na Tabela 1, tem-se as características gerais de cada prédio, a área construída e as áreas úteis de cada tipo de uso encontrado nos prédios - salas de aula, áreas de permanência temporária (circulações, depósitos, sanitários), outros tipos de uso (administrativo, laboratórios, salas de professores, auditórios, copas) e áreas cobertas abertas. 
OLIVEIRA, Wagner Costa; LEITZKE, Rodrigo Karini; CUNHA, Eduardo Grala da

Eficiência energética em prédios de salas de aula naturalmente ventilados

Figura 1 - Imagens dos projetos analisados
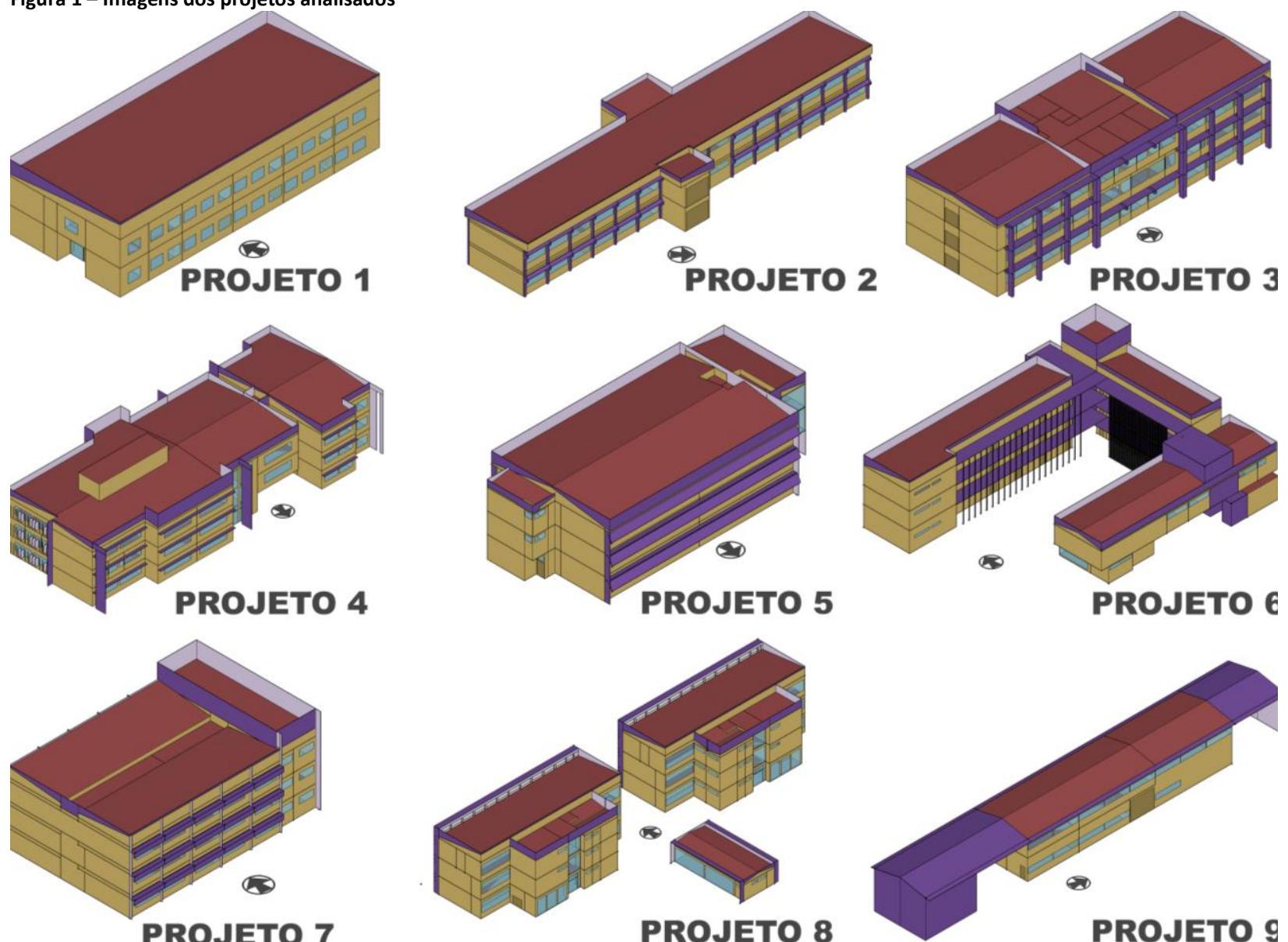

PROJETO 8

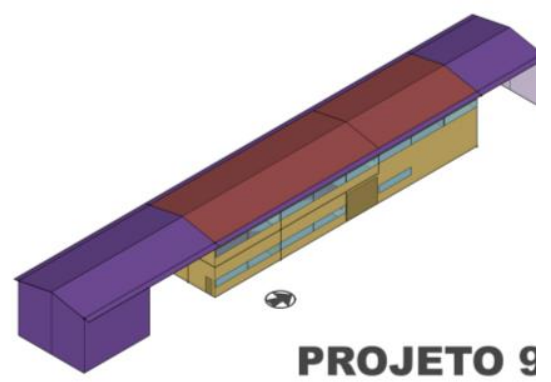

Fonte: os autores.

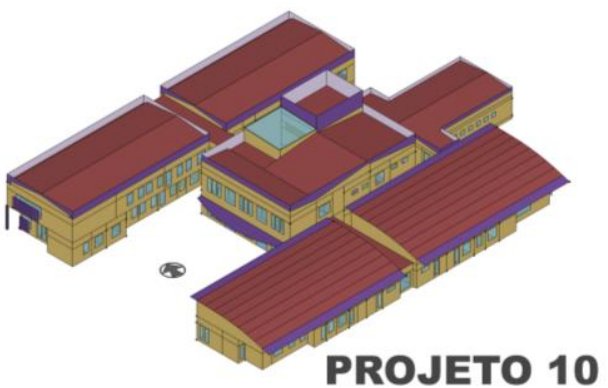

Tabela 1-Características dos projetos

\begin{tabular}{cccccccc}
\hline ID & $\begin{array}{c}\mathbf{N}^{\circ} \text { de } \\
\text { Pav. }\end{array}$ & Salas de Aula & Outros usos & Perm. Temporária & $\begin{array}{c}\text { Cobertura } \\
\text { Aberta }\end{array}$ & Total & Cidade \\
\hline 1 & 2 & $1.011,80$ & 0,00 & 323,75 & 0,00 & $1.355,55$ & Sertão (RS) \\
\hline 2 & 2 & 616,96 & 0,00 & 340,70 & 0,00 & 957,66 & $\begin{array}{c}\text { Santa Vitória do } \\
\text { Palmar (RS) }\end{array}$ \\
\hline 3 & 3 & 610,48 & 913,74 & 615,36 & 0,00 & $2.139,58$ & Pelotas (RS) \\
\hline 4 & 3 & 938,98 & 641,57 & 889,66 & 0,00 & $2.470,21$ & Santa Maria (RS) \\
\hline 5 & 3 & 953,70 & 60,20 & 651,49 & 0,00 & $1.665,39$ & Santa Maria (RS) \\
\hline 6 & 3 & 668,22 & 590,22 & 104,92 & 598,00 & $1.961,99$ & Santa Maria (RS) \\
\hline 7 & 3 & 487,52 & 501,14 & 385,56 & 0,00 & $1.374,22$ & Santa Maria (RS) \\
\hline 8 & 3 & 790,40 & 474,12 & 833,71 & 0,00 & $2.098,23$ & Cachoeira do Sul (RS) \\
\hline 9 & 2 & 140,59 & 327,34 & 140,98 & 298,84 & 907,75 & Santa Maria (RS) \\
\hline 10 & 2 & 271,21 & $1.044,12$ & 929,22 & 0,00 & $2.244,55$ & Santa Maria (RS) \\
\hline
\end{tabular}

Fonte: os autores. 
A maioria dos projetos selecionados para o estudo possuem, além das salas de aula, outros tipos de usos integrando o programa de necessidades. Dentre os principais, destacam-se as salas de professores e ambientes administrativos em geral. Também estão presentes diferentes tipos de laboratórios de ensino. Três dos projetos possuem auditórios. É importante discriminar os diferentes tipos de ambientes presentes em um edifício, pois cada um deles tem características físicas, cargas térmicas (iluminação, equipamentos, usuários) e agendas de utilização diferentes, fatores determinantes na avaliação da eficiência energética dos espaços e, consequentemente, na avaliação final.

A proporção entre os diversos tipos de ambientes é outro aspecto que influencia no resultado da simulação, considerando que os ambientes de permanência temporária (como circulações, depósitos, sanitários) recebem automaticamente a melhor avaliação. A Figura 2 ilustra esta relação nos dez projetos integrantes deste estudo.

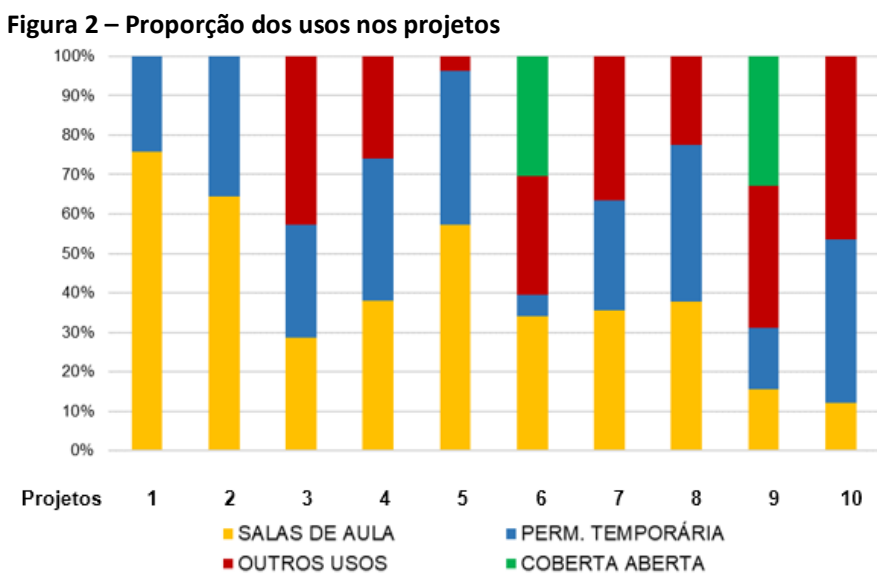

Fonte: os autores

O segundo grupo de características a serem apresentadas refere-se aos aspectos construtivos da envoltória dos projetos analisados. A Tabela 2 mostra as diferentes camadas das paredes externas e suas características físicas: transmitância térmica (U), capacidade térmica (CT), atraso térmico e a absortância da face externa ( $\alpha$ ).

Quanto às paredes, verifica-se que o sistema tradicional de construção, composto de paredes de tijolos cerâmicos rebocados em ambas as faces, é o mais frequente nos projetos analisados. Apenas dois deles apresentam sistemas construtivos pré-moldados utilizando placas de concreto, ambos sem revestimento interno ou externo.

Sobre a absortância, vários projetos não especificam a cor das paredes externas nas pranchas do projeto arquitetônico ou nos memoriais, deixando essa definição a cargo da fiscalização da obra, durante sua execução. Para esses casos, assumiu-se o valor médio de 0,5 para este parâmetro.

A Tabela 3 informa os materiais e espessuras que compõem as diferentes camadas das coberturas: as telhas, o tipo de laje existente e, quando presente, o tipo de forro empregado. Por fim, são apresentadas as características térmicas dos diferentes sistemas de cobertura.

As combinações dos três tipos de telhas, cinco tipos de lajes e dois tipos de forros (além da ausência de forro) geraram nove sistemas de coberturas. Em relação aos prérequisitos específicos para as coberturas, todos os projetos conseguiram manter a transmitância térmica abaixo do valor limite de $1,50 \mathrm{~W} / \mathrm{m}^{2} \cdot \mathrm{K}$ determinado no RTQ-C (INMETRO, 2010) para ambientes não condicionados. Quanto ao pré-requisito da absortância da cobertura (cujo limite imposto pelo RTQ-C é de 0,50), as coberturas de 
fibrocimento foram reprovadas, por não terem nenhum tipo de pintura especificada para clarear as telhas.

Tabela 2 - Características das paredes externas dos projetos analisados

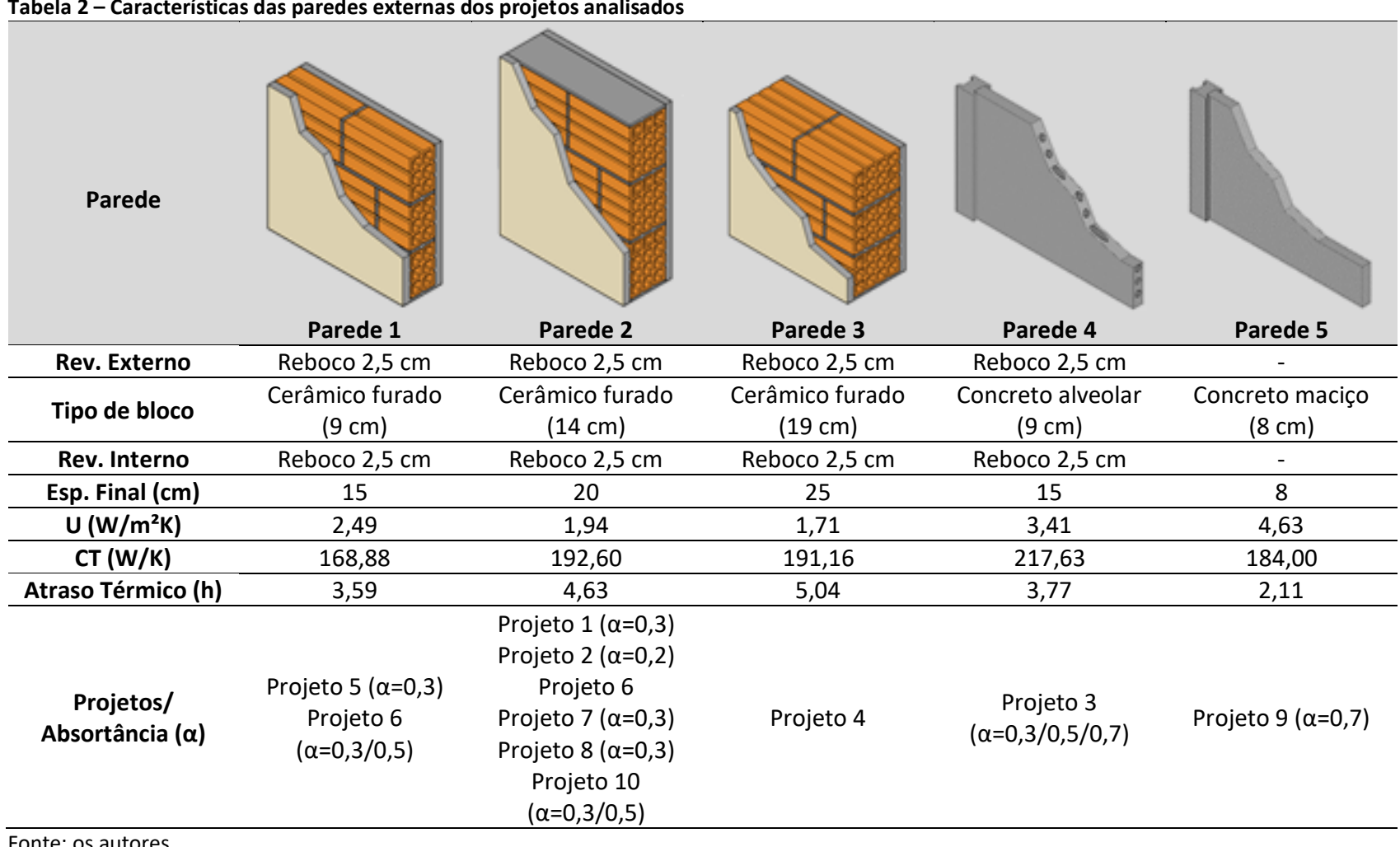

Fonte: os autores.

Tabela 3 - Características das coberturas dos projetos analisados

\begin{tabular}{|c|c|c|c|c|c|c|c|}
\hline \multirow{2}{*}{ ID } & \multicolumn{3}{|c|}{ Componentes da Cobertura } & \multirow{2}{*}{$\mathrm{U}\left(\mathrm{W} / \mathrm{m}^{2} \mathrm{~K}\right)$} & \multirow{2}{*}{ CT (W/K) } & \multirow{2}{*}{$\begin{array}{c}\text { Atraso } \\
\text { Térmico (h) }\end{array}$} & \multirow{2}{*}{$\alpha$} \\
\hline & Telha & Laje & Forro & & & & \\
\hline 1 & $\begin{array}{c}\text { Aluzinc } 0,5 \mathrm{~mm} \\
\text { natural }\end{array}$ & Concreto $15 \mathrm{~cm}$ & - & 1,08 & 384,74 & 10,87 & 0,05 \\
\hline 2 & Fibrocimento $6 \mathrm{~mm}$ & Concreto $20 \mathrm{~cm}$ & Fibra mineral & 0,74 & 470,04 & 15,04 & 0,7 \\
\hline 3 & Aluzinc + EPS $50 \mathrm{~mm}$ & Alveolar $20 \mathrm{~cm}$ & - & 0,40 & 208,76 & 14,36 & 0,05 \\
\hline 4 & Aluzinc + EPS $30 \mathrm{~mm}$ & Concreto $10 \mathrm{~cm}$ & - & 0,57 & 271,85 & 13,43 & 0,05 \\
\hline 5 & Fibrocimento $8 \mathrm{~mm}$ & $\begin{array}{c}\text { Tavela EPS } 12 \\
\mathrm{~cm}\end{array}$ & Gesso Acartonado & 0,96 & 141,67 & 6,84 & 0,7 \\
\hline 6 & Fibrocimento $8 \mathrm{~mm}$ & $\begin{array}{c}\text { Tavela EPS } 12 \\
\text { cm }\end{array}$ & - & 1,23 & 171,85 & 6,46 & 0,7 \\
\hline 7 & $\begin{array}{c}\text { Aluzinc } 0,5 \mathrm{~mm} \\
\text { natural }\end{array}$ & $\begin{array}{c}\text { Tavela EPS } 12 \\
\mathrm{~cm}\end{array}$ & Gesso Acartonado & 0,88 & 130,99 & 8,29 & 0,05 \\
\hline 8 & $\begin{array}{c}\text { Aluzinc } 0,5 \mathrm{~mm} \\
\text { natural }\end{array}$ & $\begin{array}{c}\text { Tavela EPS } 12 \\
\mathrm{~cm}\end{array}$ & - & 1,22 & 122,17 & 7,16 & 0,05 \\
\hline 9 & $\begin{array}{c}\text { Aluzinc } 0,5 \mathrm{~mm} \\
\text { natural }\end{array}$ & $\begin{array}{c}\text { Tavela } \\
\text { Cerâmica } 15 \\
\text { cm }\end{array}$ & Gesso Acartonado & 0,77 & 197,73 & 9,57 & 0,05 \\
\hline 10 & $\begin{array}{c}\text { Aluzinc } 0,5 \mathrm{~mm} \\
\text { natural }\end{array}$ & $\begin{array}{c}\text { Tavela EPS } 12 \\
\mathrm{~cm}\end{array}$ & Gesso Acartonado & 0,88 & 130,99 & 8,29 & 0,05 \\
\hline
\end{tabular}

\section{Aplicação do RTQ-C}

Após a caracterização dos projetos, passou-se à etapa de determinação do seu nível de eficiência, através da metodologia do RTQ-C (INMETRO, 2010). O primeiro passo foi a verificação do atendimento aos pré-requisitos gerais, referentes ao aquecimento de 
água e aos circuitos elétricos da edificação. Tais pré-requisitos foram atendidos em todos os projetos.

A seguir, de acordo com o edifício, pode-se escolher um dos métodos oferecidos pelo regulamento para realizar a avaliação: o prescritivo ou a simulação. Para edificações naturalmente ventiladas, o nível de eficiência deve ser determinado através do método prescritivo, utilizando a Equação Geral, representada na Equação 1 (INMETRO, 2010).

$P T=0,30 \cdot\left\{\left(E q N u m E n v \cdot \frac{A C}{A U}\right)+\left(\frac{A P T}{A U} \cdot 5+\frac{A N C}{A U} \cdot E q N u m V\right)\right\}+0,30 \cdot(E q N u m D P I)+$ $0,40 \cdot\left\{\left(E q N u m C A \cdot \frac{A C}{A U}\right)+\left(\frac{A P T}{A U} \cdot 5+\frac{A N C}{A U} \cdot E q N u m V\right)\right\}+b_{0}^{1}$

Onde:

PT: pontuação total; EqNumEnv: equivalente numérico da envoltória; AC: área condicionada; AU: área útil; APT: área de permanência temporária; ANC: área não condicionada; EqNumV: equivalente numérico de ventilação; EqNumDPI: equivalente numérico de iluminação; EqNumCA: equivalente numérico do sistema de condicionamento de ar; b: pontos de bonificação.

Contudo, como os prédios são naturalmente ventilados em sua totalidade, todos os termos referentes à área condicionada podem ser simplificados, tendo-se assim a Equação 2.

$P T=0,70 \cdot\left(\frac{A P T}{A U} \cdot 5+\frac{A N C}{A U} \cdot E q N u m V\right)+0,30 \cdot(E q N u m D P I)+b_{0}^{1}$

Eq. 2

Onde:

PT: pontuação total; APT: área de permanência temporária; AU: área útil; ANC: área não condicionada; EqNumV: equivalente numérico de ventilação; EqNumDPI: equivalente numérico de iluminação; b: pontos de bonificação.

\section{Simulação do conforto térmico: EqNumV}

A determinação do Equivalente Numérico de Ventilação (EqNumV) depende da simulação termoenergética dos prédios estudados, para determinar o percentual de horas ocupadas em conforto (POC) dos ambientes de permanência prolongada. $O$ processo se divide em três etapas principais: modelagem geométrica e numérica do projeto, configuração dos dados de saída necessários para avaliar o conforto e análise dos resultados, de acordo com a hipótese de conforto térmico selecionada.

A primeira etapa da criação dos modelos para a simulação energética é a modelagem geométrica da edificação, realizada no software OpenStudio e seu respectivo plugin para o SketchUp. Dado que o objetivo neste trabalho é a avaliação do percentual de horas ocupadas em conforto de cada um dos ambientes, optou-se por modelar cada um dos ambientes dos projetos como uma zona térmica individual.

As próximas etapas (configuração das características físicas dos materiais componentes dos elementos de vedação das edificações, agendas de utilização, definição das cargas internas) foram realizadas no programa OpenStudio. Foram criadas agendas de funcionamento e ocupação diferenciadas para cada tipo de uso encontrado: salas de aula e laboratórios de ensino, salas administrativas, salas de professores, cantinas e lancherias, auditórios e ambientes de permanência transitória (circulações, escadas, banheiros, depósitos, almoxarifados). A Figura 3 ilustra as diferentes agendas de ocupação consideradas neste trabalho. 


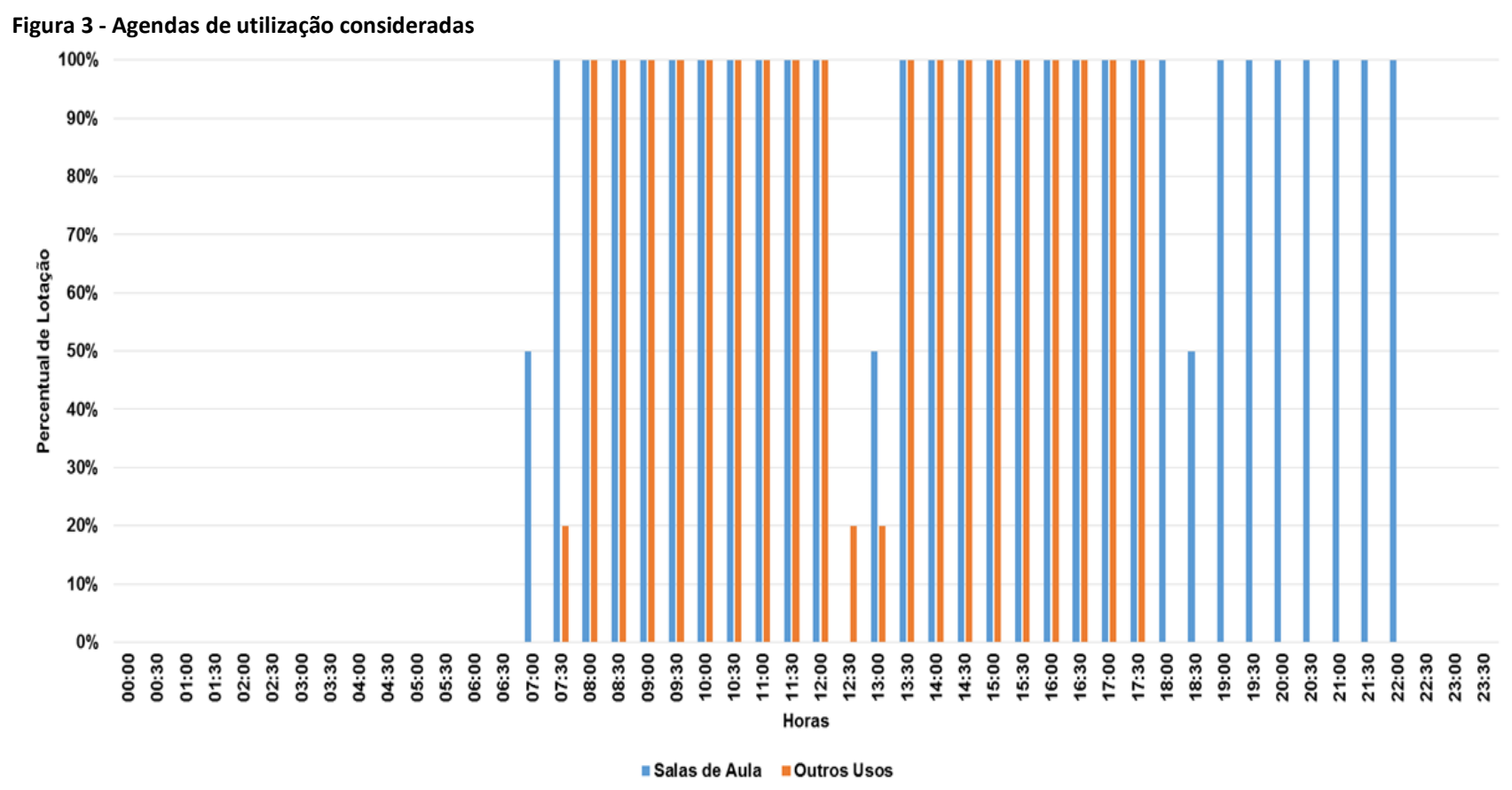

Fonte: os autores.

As densidades populacionais foram determinadas de acordo com os dados da NBR 9077 (ABNT, 2001). A Tabela 4 apresenta os valores utilizados nos modelos deste trabalho. Em relação ao nível de atividade dos ocupantes do prédio, utilizou-se a referência da NBR 16401 (ABNT, 2008), que define entre 1,0 met e 1,2 met (ou entre $105 \mathrm{~W}$ e $124 \mathrm{~W}$ ) o nível de atividade para pessoas utilizando as roupas apropriadas para cada estação, e em atividade leve de escritório. Considerou-se o valor de $120 \mathrm{~W}$ para a atividade dos ocupantes das edificações.

\begin{tabular}{cc} 
Tabela 4 - Densidades de ocupação consideradas \\
\hline Uso & Detalhamento \\
\hline Salas de aula & $1,5 \mathrm{~m}^{2} /$ pessoa \\
\hline Laboratórios de Ensino & $5,0 \mathrm{~m}^{2} /$ pessoa \\
\hline Salas Administrativas & $7,0 \mathrm{~m}^{2} /$ pessoa \\
\hline Salas de Professores & $7,0 \mathrm{~m}^{2} /$ pessoa \\
\hline Cantinas e Lancherias & $1,0 \mathrm{~m}^{2} /$ pessoa \\
\hline Auditórios & $1,0 \mathrm{~m}^{2} /$ pessoa \\
\hline Salas de estudos & $4,0 \mathrm{~m}^{2} /$ pessoa \\
\hline Consultórios/Gabinetes & 3 pessoas \\
\hline
\end{tabular}

Fonte: adaptado de ABNT, 2008.

As cargas de equipamentos também foram definidas de acordo com os parâmetros estipulados pela NBR 16401 (ABNT 2008). As densidades de calor dissipadas pelos equipamentos nos diversos tipos de ambientes utilizados estão relacionadas no Tabela 5.

\begin{tabular}{cc} 
Tabela 5 - Densidade de carga interna de equipamentos por tipo de uso da sala \\
\hline Uso & Carga Interna \\
\hline Salas de aula & \multirow{2}{*}{$5,0 \mathrm{~W} / \mathrm{m}^{2}$} \\
\hline Auditórios & \\
\hline Salas de Estudos & $21,5 \mathrm{~W} / \mathrm{m}^{2}$ \\
\hline Salas Administrativa & \\
\hline Salas de Professores & $21,5 \mathrm{~W} / \mathrm{m}^{2}$
\end{tabular}

Fonte: adaptado de ABNT, 2008. 
A última etapa da definição das cargas internas da edificação foi a configuração das cargas provenientes da iluminação interna, baseada nos projetos elétricos e luminotécnicos de cada edificação. Destaca-se que, para o Projeto 3, não foram obtidos os projetos elétricos da edificação. Portanto, para esse edifício, especificamente, foram utilizadas as densidades de potência de iluminação recomendadas pelo RTQ-C (INMETRO, 2010) para o Nível A de eficiência energética.

As próximas etapas da modelagem foram realizadas utilizando o EnergyPlus, em sua versão 8.8, com o componente IDFEditor. As simulações finais foram feitas com o componente EP-Launch do mesmo programa.

Para a ventilação natural, adotou-se o modelo de rede de fluxo de ar (Airflow Network), permitindo que o programa de simulação determine, em cada ambiente, a quantidade e velocidade do ar proveniente do exterior e considere as interações do ar entre ambientes adjacentes (utilizando-se o controle MultizoneWithoutDistribution), simulando assim o efeito da ventilação cruzada. A operação das janelas foi controlada com o controle ASHRAE55Adaptive, baseado na temperatura média da faixa de conforto adaptativo da ASHRAE 55/2017. Utilizaram-se os coeficientes de pressão calculados automaticamente pelo programa (os quais são limitados a edificações com geometria retangular). Para o entorno, foi selecionada a opção "Urbano", condição mais apropriada ao ambiente dos campi onde os prédios estão localizados.

O modelo de conforto adaptativo do ASHRAE Standard 55 (ASHRAE, 2010) é baseado nos estudos de de Dear e Brager (2002), que pesquisaram dados coletados em mais de 160 prédios de escritórios espalhados por quatro continentes e perceberam que a adaptação dos usuários tem um papel fundamental na percepção do conforto térmico, pois os ocupantes dos edifícios com ventilação natural demonstram uma maior tolerância em temperaturas mais elevadas (DE DEAR; BRAGER, 2002). Para determinar a zona de $80 \%$ de aceitabilidade, os autores propõem a Equação 3.

$T_{\text {conf }}=17,8^{\circ} \mathrm{C}+0,31 \cdot T_{m m} \pm 3,5^{\circ} \mathrm{C}$

Eq. 3

Onde Tconf: temperatura média de conforto, Tmm: temperatura média mensal.

Para realizar as simulações, utilizou-se o arquivo climático de Santa Maria (BRA_Santa.Maria.839360_SWERA.epw), onde a maioria dos projetos analisados está situada. Como o RTQ-C (INMETRO, 2010) permite a utilização de arquivos de outras cidades da mesma zona bioclimática, nos casos em que não há dados disponíveis para a cidade da edificação avaliada, o arquivo foi utilizado para todos os projetos.

A Figura 4 apresenta uma sobreposição das temperaturas médias diárias do arquivo climático utilizado com os limites para $80 \%$ de aceitabilidade do conforto adaptativo calculados a partir deles. Observa-se que, de abril a outubro, a temperatura média mensal encontra-se abaixo do limite inferior da zona de conforto.

Após a conclusão dos modelos, foram selecionadas as variáveis de saída necessárias para a avaliação do conforto nos ambientes: a temperatura do ar externo e a temperatura operativa em cada zona térmica, para as horas em que estas estão efetivamente ocupadas. Com esses dados, realizou-se a análise das temperaturas operativas obtidas, para verificar se a zona térmica estava em situação de conforto térmico. Após a determinação do POC, atribuiu-se o nível de eficiência de cada ambiente, conforme a Tabela 6.4 do RTQ-C (INMETRO, 2010). Finalmente, efetuou-se a 
ponderação do equivalente numérico de cada nível de eficiência pela sua fração de área em relação à área útil total do projeto.

Figura 4 - Temperaturas do arquivo climático e limites do conforto adaptativo

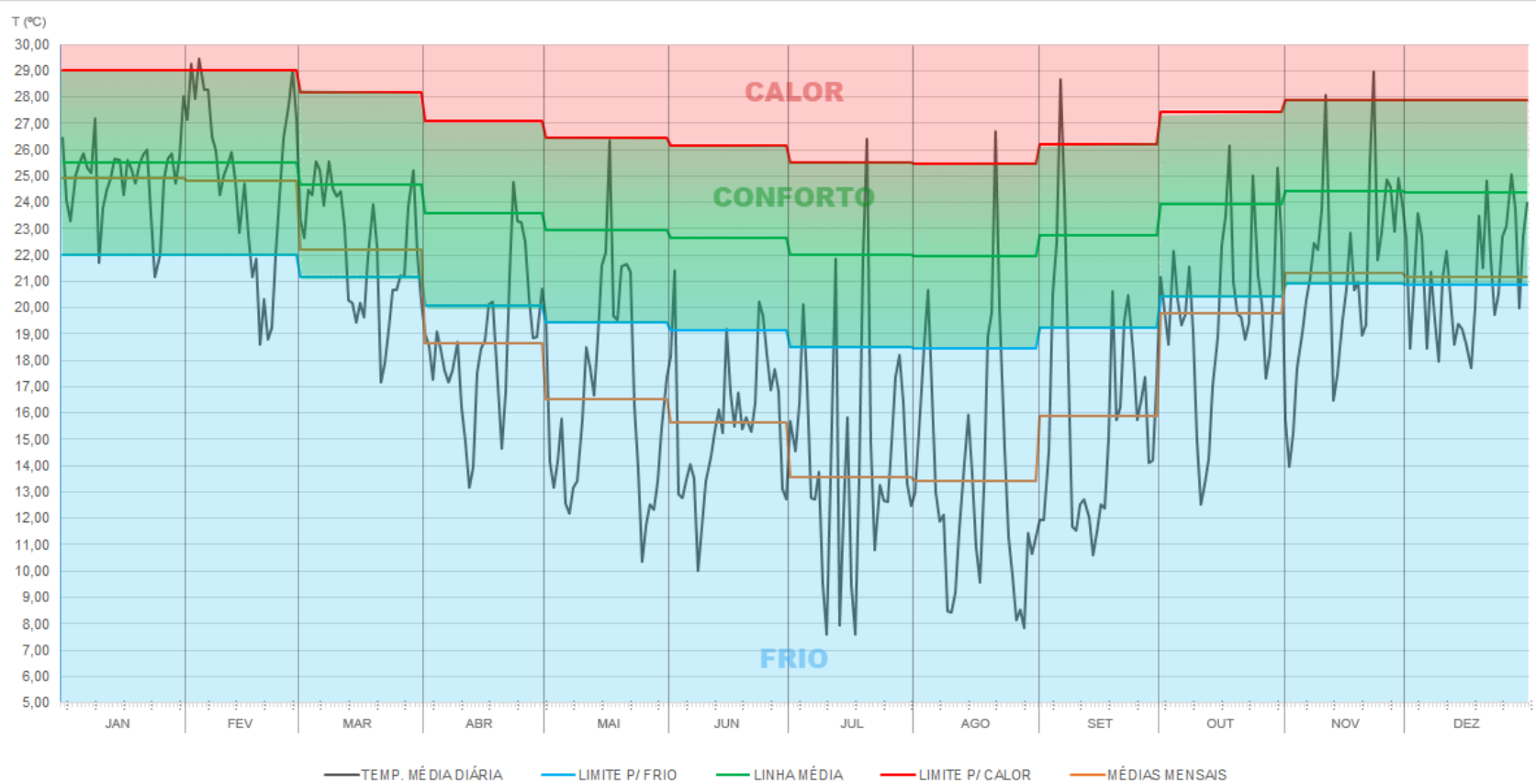

Fonte: os autores.

Determinação da eficiência do sistema de iluminação: EqNumDPI

A determinação do nível de eficiência do sistema de iluminação dos projetos passou pelas seguintes etapas: análise do nível de eficiência pelo método da área do edifício, verificação do atendimento aos pré-requisitos específicos, comparação dos resultados das duas etapas para cada ambiente, ponderação do nível de eficiência de acordo com a potência instalada, e determinação do EqNumDPI. Para aplicação do método da área do edifício, utilizaram-se as densidades de potência de iluminação para escolas e universidades da Tabela 4.1 do RTQ-C (INMETRO, 2010), conforme a Tabela 6.

Tabela 6 - Densidade de potência limite para escolas e universidades

\begin{tabular}{cc}
\hline Nível de Eficiência & $\begin{array}{c}\text { Densidade de potência máxima } \\
\left(\mathbf{W} / \mathbf{m}^{\mathbf{2}}\right)\end{array}$ \\
\hline Nível A & 10,70 \\
\hline Nível B & 12,30 \\
\hline Nível C & 13,90 \\
\hline Nível D & 15,50 \\
\hline
\end{tabular}

Fonte: INMETRO (2010).

O primeiro passo realizado foi o cálculo da área total dos projetos. Para a avaliação do sistema de iluminação, devem ser consideradas as áreas cobertas abertas, diferentemente da simulação computacional. Com esse valor, procedeu-se a determinação das potências de iluminação limites para cada nível de eficiência energética, utilizando os valores do Tabela 6.

A seguir, comparou-se a potência total de iluminação instalada no projeto (verificada através dos projetos elétricos) com os limites calculados, para determinar o nível de eficiência do projeto. Na segunda etapa da avaliação, três pré-requisitos precisam ser atendidos pelo sistema de iluminação de um compartimento, para que este possa 
receber o nível A de eficiência energética: a divisão dos circuitos de iluminação, a contribuição da luz natural e o desligamento automático da iluminação.

O Quadro 1 demonstra a relação entre o atendimento dos pré-requisitos e o nível de eficiência máximo que pode ser alcançado. Observa-se que, para que o sistema de iluminação atinja o nível $A$, é necessário atender às três condições impostas pelo RTQ-C.

Quadro 1 - Densidade de potência limite para escolas e universidades

\begin{tabular}{|c|c|c|c|}
\hline Pré-Requisito & Nível A & Nível B & Nível C \\
\hline Divisão dos circuitos & SIM & SIM & SIM \\
\hline Aproveitamento da luz natural & SIM & SIM & \\
\hline Desligamento automático & SIM & & \\
\hline
\end{tabular}

Fonte: INMETRO (2010).

A última fase dessa etapa é a determinação do equivalente numérico de cada ambiente da edificação, considerando os resultados das duas etapas anteriores. A soma de todos os equivalentes dos ambientes ponderados por suas respectivas potências de iluminação determina, enfim, o EqNumDPI.

\section{Cálculo dos pontos de bonificação: $b$}

São três as possibilidades de um projeto obter um ponto de bonificação na pontuação final, segundo o RTQ-C (INMETRO, 2010): comprovar uma economia de $40 \%$ no uso de água, adotando medidas que racionalizem o consumo; utilizar fontes de energia renovável que acarretem economia comprovada de $10 \%$ no consumo de eletricidade do prédio; ou incorporar ao projeto sistemas de cogeração e inovações tecnológicas que garantam uma redução de 30\% no consumo de energia da edificação.

Através da leitura dos projetos estudados não se identificou em nenhum deles qualquer iniciativa que atendesse à segunda ou à terceira hipótese para bonificação; assim, este trabalho limitou a avaliação do ponto de bonificação à verificação do uso racional de água.

A metodologia indicada pelo Manual para Aplicação do RTQ-C (INMETRO, 2010) para a determinação da economia de água consiste, resumidamente, em comparar o consumo anual de água de um prédio com as mesmas características de população e com equipamentos hidráulicos convencionais (chamado de consumo de referência) com o consumo do prédio real, que leva em consideração as iniciativas para redução do uso de água.

Primeiramente, buscou-se nos memoriais e orçamentos das obras indícios da utilização de equipamentos hidráulicos econômicos (torneiras para lavatório, mictório, vasos sanitários e torneiras para pias de cozinha). A seguir, utilizando as tabelas de frequência de uso e de consumo de água dos equipamentos hidrossanitários padrão, calculou-se o consumo diário de referência. Em seguida, calculou-se o consumo com os equipamentos econômicos. Através da comparação entre os resultados, obteve-se o percentual de economia de água atingido no projeto e o respectivo valor da bonificação.

Determinação do nível de eficiência energética

Após o cálculo de todos os valores necessários, a Pontuação Total (PT) de cada projeto foi calculada utilizando a Equação Geral do RTQ-C (INMETRO, 2010). Com a pontuação total, utilizou-se a Tabela de Classificação Geral do regulamento para verificar o Nível de Eficiência Energética dos projetos. A tabela em questão está reproduzida na Tabela 7. 
Tabela 7 - Classificação geral segundo o RTQ-C

\begin{tabular}{cc}
\hline Pontuação Total (PT) & Nível de Eficiência \\
\hline$>4.5$ a 5 & $\mathrm{~A}$ \\
\hline$>3.5 \mathrm{a}<4.5$ & $\mathrm{~B}$ \\
\hline$\geq 2,5 \mathrm{a}<3,5$ & $\mathrm{C}$ \\
\hline$\geq 1,5 \mathrm{a}<2,5$ & $\mathrm{D}$ \\
\hline$<1,5$ & $\mathrm{E}$ \\
\hline
\end{tabular}

Fonte: INMETRO (2010).

Proposição de medidas de aprimoramento aos projetos

A análise dos resultados obtidos em cada etapa do processo de etiquetagem evidenciou os pontos em que o desempenho de cada projeto poderia ser aprimorado, melhorando a pontuação final da avaliação de eficiência energética.

Para a proposição de intervenções de projeto visando o aumento da classificação de eficiência energética dos projetos até o nível máximo, deu-se preferência para as modificações menos intrusivas nos projetos, verificando a pontuação final a cada modificação implementada. Assim, primeiramente, foram sugeridas correções para maximizar a pontuação de bonificação merecida em cada projeto. Em segundo lugar, foram feitas modificações no sistema de iluminação, visando elevar a nota do EqNumDPI. Por fim, caso ainda assim o projeto não tenha alcançado a pontuação mínima para receber o nível A, passou-se a analisar as envoltórias das edificações.

\section{Simulação do consumo de eletricidade}

Após ter sido realizada a etapa de intervenção nos projetos para que estes alcançassem a ENCE Nível A, procedeu-se a realização de simulações de consumo de energia elétrica, a fim de comparar o desempenho dos dez prédios analisados na hipótese de estes serem condicionados artificialmente.

Para estas simulações, foram consideradas as mesmas agendas de ocupação, iluminação e equipamentos definidas nas simulações de conforto térmico. A população do prédio também se manteve a mesma. Foram realizadas intervenções apenas nos sistemas necessários para atingir o Nível A de eficiência energética.

O sistema de ventilação natural de todos os modelos foi alterado. Assim, em vez de utilizar o Airflow Network com esquadrias operáveis durante os horários de funcionamento do prédio, utilizou-se o objeto Infiltration: Design Flow Rate para atribuir trocas de ar através de infiltração para os ambientes de trabalho.

O sistema de ar condicionado definido para os modelos foi o sistema Package Transfer Heat Pump (PTHP), equivalente aos aparelhos convencionais de janela ou do tipo split. O coeficiente de performance (COP) dos aparelhos é o mesmo definido pelo Programa Brasileiro de Etiquetagem para que os condicionadores de ar deste tipo atinjam o Nível A, ou seja, 3,22 W/W. O dimensionamento da carga térmica de cada ambiente e da capacidade do aparelho para atender a demanda de cada sala foi realizado automaticamente pelo programa de simulação. $O$ termostato para acionamento do sistema de condicionamento do ar foi configurado em $21^{\circ} \mathrm{C}$ para aquecimento e $25,5^{\circ} \mathrm{C}$ para resfriamento, conforme a NBR 16401 (ABNT, 2008).

Com essas simulações, foram obtidos os dados relativos ao consumo anual de energia elétrica dos sistemas de ar condicionado de cada um dos prédios. Para que os dados pudessem ser comparados, o valor total do consumo em cada prédio foi dividido pela respectiva área condicionada, gerando um índice de consumo $\left(\mathrm{em} \mathrm{kWh} / \mathrm{m}^{2}\right)$ que possibilita a comparação entre os projetos estudados. 


\section{Resultados}

Nesta seção são apresentados os resultados de cada etapa da verificação de eficiência: simulações de conforto térmico, avaliação da iluminação, cálculo da bonificação e determinação do nível de eficiência de cada projeto. Também são apresentadas as melhorias propostas e a comparação entre os consumos de eletricidade para condicionamento dos prédios.

\section{Resultados das simulações de conforto térmico}

A Tabela 8 demonstra os dados de área não condicionada, área de permanência temporária, equivalente numérico de ventilação calculado e nível de eficiência correspondente para cada um dos projetos.

\begin{tabular}{ccccc}
\multicolumn{6}{l}{ Tabela 8 - Resultados do cálculo do EqNumV dos projetos } \\
\hline Projeto & ANC & APT & EqNumV & ENCE \\
\hline 1 & $1.011,80$ & 323,75 & 4,89 & A \\
\hline 2 & 616,96 & 340,70 & 4,50 & A \\
\hline 3 & $1.524,22$ & 615,36 & 3,59 & B (EqNumV) \\
\hline 4 & $1.580,55$ & 889,66 & 4,30 & B \\
\hline 5 & $1.013,90$ & 651,49 & 4,40 & B \\
\hline 6 & $1.259,07$ & 104,92 & 3,23 & C \\
\hline 7 & 988,66 & 385,56 & 4,77 & A \\
\hline 8 & $1.264,52$ & 833,71 & 4,58 & A \\
\hline 9 & 467,93 & 140,98 & 2,65 & C \\
\hline 10 & $1.315,33$ & 929,92 & 3,56 & B
\end{tabular}

Fonte: os autores.

Os resultados obtidos na avaliação do EqNumV refletem a diversidade de soluções de projeto encontradas, variando entre 2,65 e 4,89. Alguns padrões, contudo, foram identificados nas análises dos valores de conforto térmico dos prédios simulados. Em primeiro lugar, constatou-se que o nível de eficiência nas salas de aula sempre foi maior do que os níveis em compartimentos com outros usos, dentro de uma mesma edificação e no mesmo pavimento. Foram encontradas maiores diferenças nos níveis de desconforto por frio, em todos os casos, o que corrobora com os dados do arquivo climático.

Edificações com partidos mais compactos e implantados sobre o eixo Norte-Sul demonstraram melhor desempenho que os prédios com partidos mais dispersos, ou aqueles implantados em diferentes orientações.

A avaliação também confirmou o fraco desempenho dos projetos com paredes de alta transmitância térmica, como painéis de concreto maciço e pouca espessura. Contudo, verificou-se que nas construções de alvenaria (desde que observada a compacidade de implantação) os resultados foram bastante satisfatórios, ainda que nenhuma das vedações especificadas tenham atendido aos pré-requisitos de transmitância térmica impostos para a avaliação prescritiva.

Resultados da avaliação dos sistemas de iluminação

A Tabela 9 demonstra os resultados da avaliação da potência de iluminação instalada, realizada através do método da área do edifício. São apresentados: a área total avaliada, as potências de iluminação limites para cada nível de eficiência energética, a potência instalada na edificação e o nível de eficiência (NE) alcançado.

Em relação aos pré-requisitos específicos, nenhum dos projetos atendeu completamente ao aproveitamento de luz natural. Em salas de aula, percebeu-se que é 
usual as luminárias serem acionadas em linhas paralelas à parede onde se localiza o quadro negro ou a tela do projetor, conforme a Figura 5.

\begin{tabular}{|c|c|c|c|c|c|c|c|}
\hline \multirow[b]{2}{*}{ Projeto } & \multicolumn{5}{|c|}{ Potências de Iluminação Limites (W) } & \multirow{2}{*}{$\begin{array}{l}\text { Potência } \\
\text { Instalada } \\
\text { (W) }\end{array}$} & \multirow[b]{2}{*}{ NE } \\
\hline & Área $\left(\mathrm{m}^{2}\right)$ & Nível A & Nível B & Nível C & Nível D & & \\
\hline 1 & $1.355,55$ & $14.504,39$ & $16.673,27$ & $18.842,15$ & $21.011,03$ & 13.560 & A \\
\hline 2 & 957,66 & $10.246,96$ & $11.779,22$ & $13.311,47$ & $14.843,73$ & 12.768 & C \\
\hline 3 & $2.139,58$ & $22.893,51$ & $26.316,83$ & $29.740,16$ & $33.163,49$ & - & - \\
\hline 4 & $2.470,21$ & $26.431,25$ & $30.383,58$ & $34.335,92$ & $38.288,26$ & 24.045 & A \\
\hline 5 & $1.374,22$ & $14.704,15$ & $16.902,91$ & $19.101,66$ & $21.300,41$ & 9.304 & A \\
\hline 6 & $1.363,99$ & $14.594,69$ & $16.777,08$ & $18.959,46$ & $21.141,85$ & 16.616 & B \\
\hline 7 & $1.655,39$ & $17.712,67$ & $20.361,30$ & $23.009,92$ & $25.658,55$ & 16.664 & A \\
\hline 8 & $2.098,23$ & $22.451,06$ & $25.808,23$ & $29.165,40$ & $32.522,57$ & 20.438 & A \\
\hline 9 & 907,75 & $9.712,93$ & $11.165,33$ & $12.617,73$ & $14.070,13$ & 10.744 & B \\
\hline 10 & $2.245,25$ & $24.024,18$ & $27.616,58$ & $31.208,98$ & $34.801,38$ & 24.430 & B \\
\hline
\end{tabular}

Fonte: os autores.

Figura 5 - Iluminação das salas de aula no Projeto 4

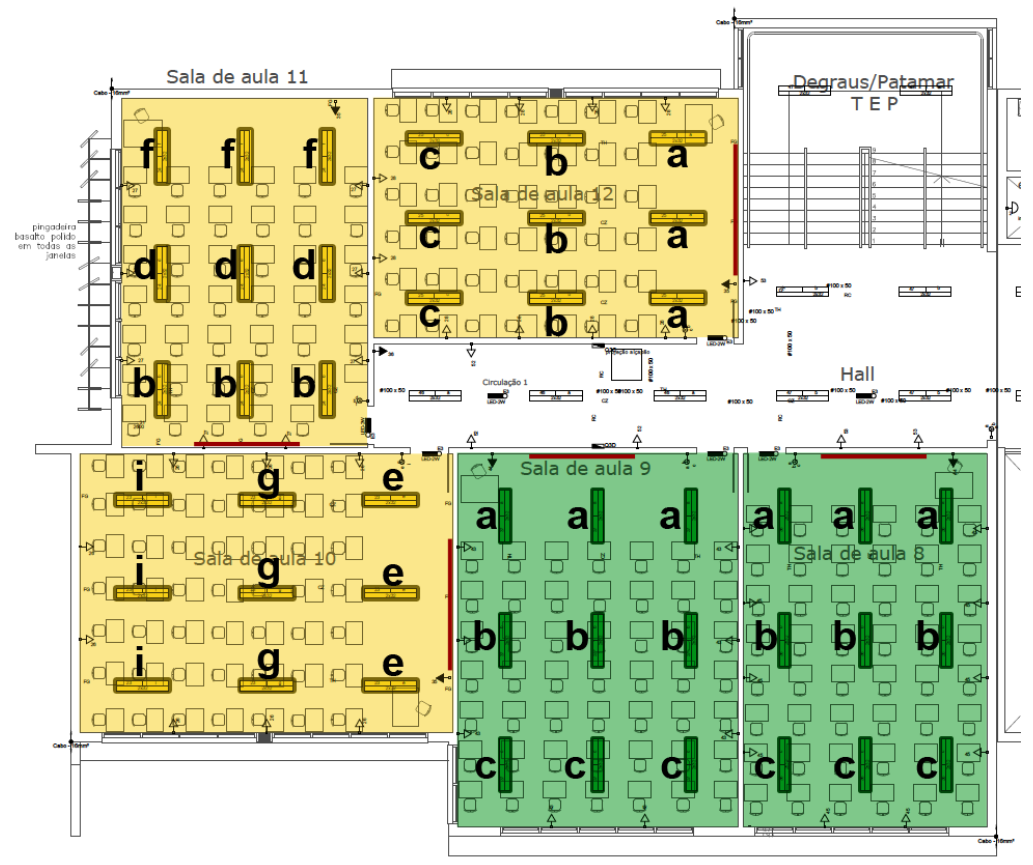

Fonte: os autores.

A seguir, realizou-se a comparação entre os resultados das duas etapas, para determinar o nível de eficiência efetivo de cada um dos ambientes dos projetos. Os resultados finais dessa comparação, com o EqNumDPI calculado e o respectivo nível de eficiência do sistema de iluminação, estão apresentados na Tabela 10.

Comparando as duas tabelas anteriores, percebe-se a importância do cumprimento dos pré-requisitos na etapa de projeto. Quatro dos prédios analisados tiveram a avaliação da potência de iluminação rebaixada em um nível por falharem em atender o prérequisito do aproveitamento da luz natural. $\mathrm{O}$ caso do Projeto 7 foi mais grave, tendo sua nota rebaixada em dois níveis. 
OLIVEIRA, Wagner Costa; LEITZKE, Rodrigo Karini; CUNHA, Eduardo Grala da

Eficiência energética em prédios de salas de aula naturalmente ventilados

\begin{tabular}{|c|c|c|c|c|c|c|}
\hline Projeto & $\begin{array}{l}\text { Pot. Total } \\
\text { (W) }\end{array}$ & $\begin{array}{l}\text { Pot. Nível A } \\
\text { (W) }\end{array}$ & $\begin{array}{l}\text { Pot. Nível B } \\
\text { (W) }\end{array}$ & $\begin{array}{l}\text { Pot. Nível C } \\
\text { (W) }\end{array}$ & EqNumDPI & ENCE \\
\hline 1 & 13.560 & 0 & 0 & 13.560 & 3,00 & C \\
\hline 2 & 12.768 & 0 & 0 & 12.768 & 3,00 & C \\
\hline 3 & $X$ & $X$ & $X$ & $X$ & $X$ & $\mathbf{X}$ \\
\hline 4 & 24.045 & 14.061 & 0 & 9.984 & 4,17 & B \\
\hline 5 & 9.304 & 3.488 & 0 & 5.816 & 3,75 & B \\
\hline 6 & 16.616 & 12.328 & 0 & 4.288 & 4,48 & B \\
\hline 7 & 16.664 & 1.912 & 0 & 14.752 & 3,27 & C \\
\hline 8 & 20.438 & 6.598 & 0 & 13.840 & 3,65 & B \\
\hline 9 & 10.744 & 0 & 4.224 & 6.520 & 3,39 & C \\
\hline 10 & & 0 & 16.174 & 8.256 & 3,66 & B \\
\hline
\end{tabular}

Fonte: os autores.

Resultados do cálculo da pontuação de bonificação

O Quadro 2 apresenta as estratégias de economia de água encontradas nas especificações e orçamentos dos projetos estudados, através dos equipamentos sanitários especificados.

Quadro 2 - Estratégias de economia empregadas nos projetos

\begin{tabular}{|c|c|c|c|c|}
\hline Projeto & Sanitário & Mictório & Lavatório & Pia \\
\hline $\mathbf{1}$ & NÃO & NÃO & SIM & NÃO \\
\hline $\mathbf{2}$ & NÃO & NÃO & SIM & NÃO \\
\hline $\mathbf{3}$ & NÃO & NÃO & NÃO & NÃO \\
\hline $\mathbf{4}$ & NÃO & SIM & SIM & SIM \\
\hline $\mathbf{5}$ & NÃO & SIM & SIM & SIM \\
\hline $\mathbf{6}$ & NÃO & SIM & SIM & SIM \\
\hline $\mathbf{7}$ & NÃO & SIM & SIM & SIM \\
\hline $\mathbf{8}$ & NÃO & SIM & SIM & SIM \\
\hline $\mathbf{9}$ & NÃO & NÃO & SIM & SIM \\
\hline $\mathbf{1 0}$ & NÃO & SIM & SIM & SIM \\
\hline
\end{tabular}

Considerando-se os dados apresentados, juntamente com a população de cada prédio, calculou-se os consumos diários de referência e reais para cada um dos projetos, para determinar o percentual de economia de água alcançado e a bonificação correspondente a este percentual. Os resultados finais são demonstrados na Tabela 11.

Tabela 11 - Bonificação alcançada em cada projeto

\begin{tabular}{|c|c|c|c|c|c|c|c|}
\hline Projeto & Alunos & Func. & Visit. & Cons. Ref. (I) & Cons. Real (I) & Economia & Bonificação \\
\hline 1 & 678 & 18 & 0 & $2.406,90$ & $2.237,40$ & $7,04 \%$ & 0,18 \\
\hline 2 & 416 & 8 & 0 & $1.668,00$ & $1.544,00$ & $7,43 \%$ & 0,19 \\
\hline 3 & $x$ & $x$ & $x$ & $x$ & $x$ & $x$ & $x$ \\
\hline 4 & 585 & 129 & 0 & $5.156,25$ & $4.044,78$ & $21,56 \%$ & 0,54 \\
\hline 5 & 637 & 21 & 0 & $2.759,65$ & $2.158,94$ & $21,77 \%$ & 0,54 \\
\hline 6 & 450 & 98 & 146 & $4.458,00$ & $3.499,28$ & $21,51 \%$ & 0,54 \\
\hline 7 & 419 & 33 & 35 & $2.396,00$ & $1.874,68$ & $21,76 \% \%$ & 0,54 \\
\hline 8 & 518 & 74 & 51 & $3.823,45$ & $2.999,70$ & $21,54 \%$ & 0,54 \\
\hline 9 & 82 & 34 & 0 & $1.254,90$ & $1.149,40$ & $8,41 \%$ & 0,21 \\
\hline 10 & 247 & 100 & 363 & 4.554 .30 & $3.573,56$ & $21,53 \%$ & 0,54 \\
\hline
\end{tabular}

Fonte: os autores.

A tabela demonstra o impacto que a seleção dos equipamentos corretos tem no consumo de água de uma edificação. $O$ fato de alguns projetos terem especificado uma válvula de mictório com um consumo reduzido acarretou uma economia em torno de $21 \%$, contra uma economia de cerca de $7 \%$ nos dois projetos que utilizaram apenas torneiras econômicas nos lavatórios e pias. 


\section{Cálculo da pontuação total dos projetos}

A Tabela 12 apresenta um resumo dos valores obtidos para todos os índices necessários ao cálculo da PT de cada um dos casos analisados: ANC, EqNumV, APT, EqNumDPI e bonificação. Ao final, a Tabela também mostra a PT atingida por cada um dos projetos, e o respectivo NE obtido.

Tabela 12 - Bonificação alcançada em cada projeto

\begin{tabular}{|c|c|c|c|c|c|c|c|}
\hline Projeto & ANC & EqNumV & APT & EqNumDPI & BON. & PT & ENCE \\
\hline 1 & $1.011,80$ & 4,89 & 323,75 & 3,00 & 0,18 & 4,52 & A \\
\hline 2 & 616,96 & 4,50 & 340,70 & 3,00 & 0,19 & 4,36 & B \\
\hline 3 & $1.524,22$ & 3,59 & 615,36 & - & - & - & B (EqNumV) \\
\hline 4 & $1.580,55$ & 4,30 & 889,66 & 4,17 & 0,54 & 4,98 & A \\
\hline 5 & $1.013,90$ & 4,40 & 651,49 & 3,23 & 0,54 & 4,75 & A \\
\hline 6 & $1.259,07$ & 3,23 & 104,92 & 4,48 & 0,54 & 4,24 & B \\
\hline 7 & 988,66 & 4,77 & 385,56 & 3,75 & 0,54 & 5,05 & $A$ \\
\hline 8 & $1.264,52$ & 4,58 & 833,71 & 3,65 & 0,54 & 4,96 & A \\
\hline 9 & 467,93 & 2,65 & 140,98 & 3,39 & 0,21 & 3,46 & C \\
\hline 10 & $1.315,33$ & 3,56 & 929,92 & 3,40 & 0,54 & 4,47 & B \\
\hline
\end{tabular}

Fonte: os autores.

A maioria dos projetos conseguiu atingir o Nível A de eficiência energética, segundo a metodologia do RTQ-C (INMETRO, 2010). O Projeto 3, por não conter informações sobre os projetos elétrico e hidrossanitário, não pôde ter sua avaliação completa, portanto somente o EqNumV foi calculado, recebendo o Nível B.

Ressalta-se a importância da pontuação de bonificação na avaliação final. Cinco dos seis projetos que alcançaram a classificação A só o fizeram devido aos pontos que obtiveram na avaliação de economia de água.

A proporção entre a ANC e a APT também se mostra como um fator importante para alcançar a pontuação para o Nível A. No Projeto 6 , as escadas e circulações são abertas ao ambiente, fazendo com que a APT ficasse restrita aos banheiros e depósitos do prédio. Neste caso, as boas pontuações obtidas no EqNumDPI e na bonificação não foram suficientes para atingir os 4,5 pontos necessários para a classificação A.

\section{Resultados da proposição de melhorias}

A primeira medida de aprimoramento implementada nos projetos refere-se ao sistema de bonificações. Com a utilização dos equipamentos eficientes em todos os pontos consumidores de água, apenas duas edificações não conseguiriam atingir os $40 \%$ de economia de água para garantir o ponto integral de bonificação. Ainda assim, tal intervenção representa uma melhora significativa na pontuação final da avaliação. $O$ cálculo do novo nível de eficiência dos projetos após a correção está no Tabela 13.

\begin{tabular}{cccccccc}
\multicolumn{7}{l}{ Tabela 13 - Pontuação total após as melhorias na bonificação } \\
\hline Projeto & ANC & EqNumV & APT & EqNumDPI & Bon. & PT & NE \\
\hline $\mathbf{1}$ & $1.011,80$ & 4,89 & 323,75 & 3,00 & 0,83 & 5,17 & A \\
\hline $\mathbf{2}$ & 616,96 & 4,50 & 340,70 & 3,00 & 1,00 & 5,17 & A \\
\hline $\mathbf{3}$ & $1.524,22$ & 3,59 & 615,36 & - & - & - & B (EqNumV) \\
\hline $\mathbf{4}$ & $1.580,55$ & 4,30 & 889,66 & 4,17 & 0,83 & 5,27 & A \\
\hline $\mathbf{5}$ & $1.013,90$ & 4,40 & 651,49 & 3,23 & 1,00 & 5,21 & A \\
\hline $\mathbf{6}$ & $1.259,07$ & 3,01 & 104,92 & 4,48 & 1,00 & 4,70 & A \\
\hline $\mathbf{7}$ & 988,66 & 4,77 & 385,56 & 3,75 & 1,00 & 5,51 & A \\
\hline $\mathbf{8}$ & $1.264,52$ & 4,58 & 833,71 & 3,65 & 1,00 & 5,42 & A \\
\hline $\mathbf{9}$ & 467,93 & 2,65 & 140,98 & 3,39 & 1,00 & 4,25 & B \\
\hline $\mathbf{1 0}$ & $1.315,33$ & 3,56 & 929,92 & 3,40 & 1,00 & 4,93 & A \\
\hline
\end{tabular}


Com essa alteração, dois dos projetos com avaliação $B$ conseguiram atingir o nível $A$ de eficiência energética. O Projeto 9 , por sua vez, melhorou sua classificação de $C$ para $B$. Como este foi o único Projeto completo que não obteve a ENCE A após esta alteração, as próximas etapas serão centradas nele.

Conforme a avaliação do sistema de iluminação do Projeto 9, constatou-se que o projeto luminotécnico não atende dois critérios importantes: a potência total instalada (10.744 W) supera o limite do nível A de eficiência, deixando-o classificado no nível B. No entanto, a não observância ao aproveitamento da luz natural faz com que o EqNumDPI seja equivalente ao nível $C$.

A primeira medida proposta para aprimorar o EqNumDPI é a adequação do acendimento das luminárias, de forma a atender o pré-requisito. Esta adequação resume-se a substituir as instalações elétricas correspondentes aos interruptores nas salas, permitindo o acionamento isolado das luzes próximas às janelas isoladamente. A segunda intervenção realizada foi a substituição das lâmpadas fluorescentes por lâmpadas de LED tubulares. Assim, a potência de iluminação instalada no prédio sofreu uma redução de $23,54 \%$, ficando em $8.215 \mathrm{~W}$. Dessa maneira, a substituição das lâmpadas faz com que a iluminação do projeto atinja o melhor nível de eficiência pelo método da área do edifício. O Tabela 14 demonstra o impacto das melhorias do sistema de iluminação na Pontuação Total do Projeto 9.

\begin{tabular}{|c|c|c|c|c|c|c|c|}
\hline Projeto & ANC & EqNumV & APT & EqNumDPI & Bon. & PT & $\mathrm{NE}$ \\
\hline 9 & 467,93 & 2,65 & 140,98 & 5,00 & 1,00 & 4,74 & A \\
\hline
\end{tabular}

Fonte: os autores.

\section{Resultados da simulação de consumo de eletricidade}

Os resultados das simulações do consumo de eletricidade para condicionamento dos projetos estudados estão apresentados no Tabela 15. Juntamente com os consumos para aquecimento e resfriamento, são apresentados os dados relativos à área condicionada de cada prédio, bem como o índice de consumo por metro quadrado. Por fim, apresenta-se o valor do EqNumV calculado nas simulações de conforto, para facilitar a comparação dos resultados obtidos na etapa atual.

Tabela 15 - Resultados das simulações do consumo de eletricidade

\begin{tabular}{|c|c|c|c|c|c|c|}
\hline Projeto & Área Condicionada $\left(\mathrm{m}^{2}\right)$ & $\begin{array}{c}\text { Consumo } \\
\text { Resfriamento } \\
\text { (kWh) }\end{array}$ & $\begin{array}{c}\text { Consumo } \\
\text { Aquecimento } \\
\text { (kWh) }\end{array}$ & $\begin{array}{l}\text { Consumo } \\
\text { Total (kWh) }\end{array}$ & $\begin{array}{c}\text { Consumo/ } \\
\text { Área }\left(\mathrm{kWh} / \mathrm{m}^{2}\right)\end{array}$ & EqNumV \\
\hline 1 & $1.011,80$ & $29.517,66$ & $19,174,04$ & $48.691,70$ & 48,12 & 4,89 \\
\hline 2 & 616,96 & $25.394,49$ & $7.887,59$ & $33.282,08$ & 53,95 & 4,50 \\
\hline 3 & $1.524,22$ & $34.472,46$ & $18.522,37$ & $52.994,83$ & 34,77 & 3,59 \\
\hline 4 & $1.580,55$ & $48.492,67$ & $14.057,06$ & $62.549,73$ & 39,57 & 4,30 \\
\hline 5 & $1.013,90$ & $36.884,51$ & $17.857,78$ & $54.472,29$ & 53,73 & 4,40 \\
\hline 6 & $1.259,07$ & $28.596,86$ & $16.869,50$ & $45.466,39$ & 36,11 & 3,01 \\
\hline 7 & 988,66 & $25.956,23$ & $7.637,34$ & $33.593,57$ & 33,98 & 4,77 \\
\hline 8 & $1.264,52$ & $29.777,29$ & $19.583,50$ & $49.360,79$ & 39,04 & 4,58 \\
\hline 9 & $8.972,42$ & $8.972,42$ & $9.732,53$ & $18.704,95$ & 39,97 & 2,65 \\
\hline 10 & $1.315,33$ & $27.699,67$ & $19.255,08$ & $46.954,75$ & 35,70 & 3,56 \\
\hline
\end{tabular}

Fonte: os autores.

Percebe-se que o índice de consumo não aparenta ter relação direta com o conforto térmico. Contudo, ao confrontar estes resultados com os dados de proporção de área por tipo de uso (Figura 2), nota-se que os prédios que apresentaram maior índice de consumo por área foram aqueles em que a área total de salas de aula, na área condicionada, era maior do que a área total correspondente a outros usos. 
O consumo para o condicionamento nas salas de aula é maior por dois motivos principais. Primeiramente, as salas de aula são utilizadas em três turnos, enquanto os demais ambientes dos prédios funcionam apenas durante a manhã e à tarde. Além disso, a carga térmica proveniente da população de usuários é maior, uma vez que a densidade populacional nas salas de aula é superior à dos demais ambientes.

Em vista disso, foram realizadas novas simulações, modificando a agenda de utilização e a densidade de população das salas de aula dos modelos, igualando-as aos ambientes administrativos. Com isso, todos os projetos analisados tornaram-se mais homogêneos, possibilitando comparações mais precisas entre os aspectos construtivos dos edifícios. Os resultados dessas simulações são apresentados na Tabela 16.

Tabela 16 - Resultados das simulações de consumo após as modificações

\begin{tabular}{|c|c|c|c|c|c|c|}
\hline Projeto & Área Condicionada $\left(\mathrm{m}^{2}\right)$ & $\begin{array}{c}\text { Consumo } \\
\text { Resfriamento } \\
\text { (kWh) }\end{array}$ & $\begin{array}{c}\text { Consumo } \\
\text { Aquecimento } \\
\text { (kWh) }\end{array}$ & $\begin{array}{l}\text { Consumo } \\
\text { Total (kWh) }\end{array}$ & $\begin{array}{c}\text { Consumo/ } \\
\text { Área }\left(\mathrm{kWh} / \mathrm{m}^{2}\right)\end{array}$ & EqNumV \\
\hline 1 & $1.011,80$ & $7.550,48$ & $12.326,87$ & $19.877,35$ & 19,65 & 4,89 \\
\hline 2 & 616,96 & $9.708,89$ & $3.361,79$ & $13.070,68$ & 21,19 & 4,50 \\
\hline 3 & $1.524,22$ & $25.225,21$ & $15.073,13$ & $40.298,34$ & 26,44 & 3,59 \\
\hline 4 & $1.580,55$ & $20.115,30$ & $8.724,95$ & $28.840,25$ & 18,25 & 4,30 \\
\hline 5 & $1.013,90$ & $13.212,76$ & $10.506,88$ & $23.719,64$ & 23,39 & 4,40 \\
\hline 6 & $1.259,07$ & $13.351,76$ & $12.999,25$ & $26.351,01$ & 20,93 & 3,01 \\
\hline 7 & 988,66 & $17.819,96$ & $6.716,09$ & $24.536,05$ & 24,82 & 4,77 \\
\hline 8 & $1.264,52$ & $11.785,47$ & $13.582,65$ & $25.368,12$ & 20,06 & 4,58 \\
\hline 9 & $8.972,42$ & $7.259,51$ & $8.963,08$ & $16.222,59$ & 34,67 & 2,65 \\
\hline 10 & $1.315,33$ & $20.602,71$ & $17.071,45$ & $37.674,16$ & 28,64 & 3,56 \\
\hline
\end{tabular}

Fonte: os autores.

Os novos resultados encontrados demonstram uma relação mais próxima com os valores do EqNumV calculados anteriormente. Agora o Projeto 9, o qual obteve a pior nota na avaliação do conforto térmico, também apresentou o valor mais alto de consumo por área. Os demais valores de consumo, no entanto, não apresentam uma correlação tão direta com os EqNumV calculados. Também vale mencionar a amplitude dos valores de consumo encontrados. Considerando-se que todos os prédios analisados nessa etapa do trabalho obtiveram o Nível A de eficiência, o consumo do Projeto 10 foi quase $90 \%$ maior que o menor dos consumos, correspondente ao Projeto 4, o que representa uma diferença considerável para projetos na mesma categoria de eficiência.

\section{Considerações finais}

Ao final das avaliações, demonstrou-se que a diferença entre os projetos de salas de aula licitados pelas IFES e a ENCE nível A de projeto, no período inicial da obrigatoriedade da etiquetagem de eficiência para esses projetos, não era grande. Comprovou-se que com pequenas modificações nos sistemas de iluminação e nos equipamentos hidráulicos dos projetos, estes conseguiriam atingir a melhor classificação de eficiência energética.

A facilidade para a obtenção da classificação máxima do RTQ-C (INMETRO, 2010), no entanto, não assegura a qualidade dos projetos. Conforme visto neste trabalho, o método de determinação de eficiência energética proposto pelo regulamento contém dispositivos que, quando explorados, podem ajudar a elevar a nota de um edifício menos eficiente.

No caso do cálculo do EqNumV, o fato das áreas de permanência temporária da edificação receberem, automaticamente, o maior equivalente numérico possível para o cálculo pode aumentar a nota de uma edificação com baixos índices de conforto térmico. Isso é especialmente verdade em casos em que os ambientes de permanência 
temporária ocupam uma área semelhante àqueles de permanência prolongada, onde realmente se desenvolvem as atividades dos usuários. Com isto em vista, a remoção das áreas de permanência temporária da avaliação pode ser uma alternativa para que o EqNumV reflita o nível de conforto da edificação de uma forma mais precisa.

A utilização da comprovação de economia de água para a obtenção do ponto extra também é um recurso que pode ser aproveitado indevidamente. $O$ processo de cálculo do percentual de economia sofre maior influência dos tipos de aparelhos utilizados; a quantidade deles ou o tamanho da população do prédio têm pouca importância no cálculo. Dessa forma, sugere-se que o regulamento adote um modelo mais rigoroso de avaliação de economia de água, utilizando consumos de referência de aparelhos sanitários mais atuais e um método que considere, ainda, a quantidade de aparelhos sanitários presentes no prédio.

Outra possibilidade é de que o ponto de bonificação seja, assim como a Pontuação Total, uma parcela composta, de forma que seja necessário combinar mais de uma possibilidade de economia dentre aquelas elencadas no regulamento para que seja possível atingir o valor integral do bônus na avaliação final.

Este trabalho mostra que a obtenção do nível máximo na avaliação proposta pelo RTQC (INMETRO, 2010) não pode ser considerada como o único parâmetro para afirmar a eficiência energética de um projeto. A avaliação do consumo de eletricidade necessário para climatizar artificialmente os edifícios estudados reforça esta afirmação: a grande diferença encontrada entre os consumos mínimo e máximo, já comentada anteriormente, serve como indicador deste fato.

Recomenda-se que, na avaliação do nível de eficiência de edificações naturalmente ventiladas, seja realizada a simulação complementar do consumo de energia na hipótese de condicionamento artificial do prédio. Então, será possível ter uma noção mais completa do comportamento energético e térmico do edifício, o que possibilita a implementação de medidas que melhorem o desempenho em ambos os aspectos.

\section{Referências}

ABNT - ASSOCIAÇÃO BRASILEIRA DE NORMAS TÉCNICAS. NBR 9077. Saídas de emergência em edifícios. Rio de Janeiro: ABNT, 2001.

ABNT - ASSOCIAÇÃO BRASILEIRA DE NORMAS TÉCNICAS. NBR 15220. Desempenho Térmico de Edificações. Parte 2: Métodos de cálculo da transmitância térmica, da capacidade térmica, do atraso térmico e do fator solar de elementos e componentes de edificações. Rio de Janeiro: ABNT, 2005 .

ABNT - ASSOCIAÇÃO BRASILEIRA DE NORMAS TÉCNICAS. NBR 15220. Desempenho Térmico de Edificações. Parte 3: Zoneamento bioclimático brasileiro e diretrizes construtivas para habitações unifamiliares de interesse social. Rio de Janeiro: ABNT, 2005b.

ABNT - ASSOCIAÇÃO BRASILEIRA DE NORMAS TÉCNICAS. NBR 16401. Instalações de ar condicionado - Sistemas centrais e unitários. Parte 2: Parâmetros de conforto térmico. Rio de Janeiro: ABNT, 2008.

ARAÚJO, João L. A questão do investimento no setor energético brasileiro: reforma e crise. Nova Economia, Belo Horizonte, v.11, n. 1, p. 77-96, jul. 2001. Disponível em:

https://revistas.face.ufmg.br/index.php/novaeconomia/article/view/382. Acesso em: 7 ago. 2020.

ASHRAE - AMERICAN SOCIETY OF HEATING, REFRIGERATING AND AIR-CONDITIONING ENGINEERS. Thermal Environmental Conditions for Human Occupancy. Atlanta: ASHRAE, 2010, 54p. 
BRASIL, CASA CIVIL. Lei n 10.295, de 17 de outubro de 2001. Dispõe sobre a Política Nacional de Conservação e Uso Racional de Energia e dá outras providências. Diário Oficial da União. Brasília, DF, 18 de outubro de 2001.

BRASIL, MINISTÉRIO DO MEIO AMBIENTE. A3P - Agenda Ambiental na Administração Pública. 5a. ed. Brasília, DF, 2009.

DE DEAR, Richard J.; BRAGER, Gail S. Thermal comfort in naturally ventilated buildings: revisions to ASHRAE Standard 55. Energy and Buildings, v. 34, n. 6, p. 549-561, 2002. DOI:https://doi.org/10.1016/S0378-7788(02)00005-1

EPE - EMPRESA DE PESQUISA ENERGÉTICA. Balanço energético nacional 2018: ano base 2017, Rio de Janeiro: EPE, 2018. Disponível em: https://www.epe.gov.br/sites-pt/publicacoes-dados-

abertos/publicacoes/PublicacoesArquivos/publicacao-303/topico-419/BEN2018_Int.pdf. Acesso em: 7 ago. 2020.

FOSSATI, M.; LAMBERTS, R. Eficiência energética da envoltória de edifícios de escritórios de Florianópolis: discussões sobre a aplicação do método prescritivo do RTQ-C. Ambiente Construído, Porto Alegre, v. 10, n. 2, p. 5969, abr. / jun. 2010.

INMETRO - INSTITUTO NACIONAL DE METROLOGIA, NORMALIZAÇÃO E QUALIDADE INDUSTRIAL. Requisitos Técnicos de Qualidade para o Nível de Eficiência Energética de Edifícios Comerciais, de Serviços e Públicos. Eletrobrás, 2010.

NAKAMURA, N. K.; MACIEL, L. F.; CARLO. J. C. Impactos de medidas de conservação de energia propostas no PBE Edifica para o nível de eficiência energética de envoltórias de um edifício naturalmente condicionado. Ambiente Construído, Porto Alegre, v. 13, n. 4, p. 105-119, out./dez. 2013. DOI:https://doi.org/10.1590/S1678 86212013000400008

OLIVEIRA, B. S.C.M. de; SANTOS, L. M. L. dos. Compras públicas como política para o desenvolvimento sustentável. Revista Administração Pública, Rio de Janeiro, n. 49, p. 189-206.

PORTAL DE COMPRAS DO GOVERNO FEDERAL. Disponível em: http://www.comprasgovernamentais.gov.br. Acesso em: 02/05/2018.

PROCELINFO - CENTRO BRASILEIRO DE INFORMAÇÃO DE EFICIÊNCIA ENERGÉTICA. Sobre o Procel, Edificações, [s.I], 2006. Disponível em: http://www.procelinfo.com.br. Acesso em: 2 mai. 2018.

SILVA, P. L.; PAGEL, E. C. Eficiência energética em edifícios públicos: um estudo de caso na sede do DETRAN/ES. ENCONTRO NACIONAL DE CONFORTO NO AMBIENTE CONSTRUÍDO. 14. Balneário Camboriú. Anais [...]. Balneário Camboriú: UNIVALI, ANTAC. 2017, p. 1479-1488.

\section{${ }^{1}$ Wagner Costa Oliveira}

Arquiteto e Urbanista. Mestre em Arquitetura e Urbanismo pela Universidade Federal de Pelotas. Arquiteto e Urbanista na Universidade Federal do Rio Grande. Endereço postal: Universidade Federal do Rio Grande, Av. Itália, Km 8, Campus Carreiros, Rio Grande - RS, Brasil, CEP 96203-900.

\section{${ }^{2}$ Rodrigo Karini Leitzke}

Bacharel em Ciência da Computação. Mestrando do Programa de Pós-Graduação em Arquitetura e Urbanismo da Universidade Federal de Pelotas. Endereço postal: Universidade Federal de Pelotas, Faculdade de Arquitetura e Urbanismo, Laboratório de Conforto e Eficiência Energética, Rua Benjamin Constant, 1359, Pelotas, RS, Brasil, CEP 96010-020.

\section{Eduardo Grala da Cunha}

Arquiteto e Urbanista. Doutor em Arquitetura pela Universidade Federal do Rio Grande do Sul. Professor associado da Faculdade de Arquitetura e Urbanismo da Universidade Federal de Pelotas. Coordenador do Programa de PósGraduação em Arquitetura e Urbanismo. Endereço postal: Universidade Federal de Pelotas, Faculdade de Arquitetura e Urbanismo, Laboratório de Conforto e Eficiência Energética, Rua Benjamin Constant, 1359, Pelotas, RS, Brasil, CEP 96010-020. 